\title{
Representations of Mathematicians in Lower Secondary Mathematics Textbooks
}

\author{
Apolo Castaneda ${ }^{1 *}$, Mario Sánchez Aguilar ${ }^{2}$, Ana Luisa Gómez-Blancarte ${ }^{2}$, \\ Avenilde Romo-Vázquez ${ }^{2}$, Javier Lezama-Andalón ${ }^{2}$, Isaías Miranda-Viramontes ${ }^{2}$ \\ ${ }^{1}$ Centro de Investigacion y de Estudios Avanzados del Instituto Politecnico Nacional, MEXICO \\ ${ }^{2}$ Instituto Politécnico Nacional, CICATA Legaria, MEXICO
}

Received 6 March 2018 - Revised 26 December 2018 - Accepted 30 December 2018

\begin{abstract}
We report on a study focused on identifying and describing the representations of mathematicians contained in Mexican textbooks of lower secondary level. We considered representations not only in the text but also in drawings, photographs, and illustrations in general. The term mathematician was understood in a broad sense: any person (or group of people) that in the textbook either (1) was explicitly referred to as a mathematician, (2) was credited with the development of a mathematical concept or tool, or (3) was displayed performing some sort of mathematical activity (such as counting, modelling, etc.). The results show that the representations that most frequently appear in the textbooks are white male mathematicians (mainly Europeans), who lived in ancient times; the representations of female mathematicians are almost nil. At the end of the paper the implications of these results are discussed, and some directions for future research are suggested.
\end{abstract}

Keywords: images of mathematicians, lower secondary education, mathematics textbooks, representations of mathematicians

\section{INTRODUCTION}

It is well known that mathematics students and the general public hold several perceptions or images - usually negative-associated with mathematics and mathematicians. Such images have been identified as factors that can be decisive for the students to feel (un)identified with, (un)attracted to, and (dis)interested in the study of mathematics (Picker \& Berry, 2000; Rock \& Shaw, 2000). Moreover, some authors suggest that the negative images of mathematics and mathematicians that some students possess are a factor that inhibits them, especially women, from pursuing an advanced degree in mathematics (Mendick, 2005; Piatek-Jimenez, 2008). But, where do these images come from?

The images that students have about mathematics and mathematicians are constituted over time and are shaped by experiences and elements coming from different social contexts. Rensaa (2006) states that these experiences and elements come from two different spheres: the public society, constituted for example by parents' and friends' images as well as representations of mathematics and mathematicians in the mass media and popular culture, and the school society, composed of teachers' and peers' images and the existing representations in school materials and content.

There are several studies focused on studying representations of mathematics and mathematicians in the public society. For instance, Furinghetti (1993) explores the representations of mathematics and mathematicians in different films and literary works, Rensaa (2006) investigates adults' images of mathematicians; Mendick (2007) analyses students' representations of mathematics and mathematicians in popular culture, and, more recently, Evans et al. (2014) investigate the representations of mathematics in advertisements included in several daily

(C) 2019 by the authors; licensee Modestum Ltd., UK. This article is an open access article distributed under the terms and conditions of the Creative Commons Attribution License (http://creativecommons.org/licenses/by/4.0/). \apolo.castaneda@cinvestav.mx (*Correspondence) $\square$ mosanchez@ipn.mx $\bigotimes$ algomezb@ipn.mx 


\section{Contribution of this paper to the literature}

- With this research we contribute to the study of the school resources (particularly lower secondary mathematics textbooks) that can shape students' images of mathematics and mathematicians.

- The research reported contributes to the study of representations of scientists and mathematicians in Latin American societies, which have been scarcely investigated.

- The study problematizes the role of mathematics textbooks in the constitution of a dominant discourse around "the mathematician", and examines some of the consequences of such discourse in students' subjectivities.

newspapers from the United Kingdom. Although there are also studies focused on the school society, some components of this society remain under-researched.

One of the most studied components of the school society are the images that students have about mathematics and mathematicians (e.g. Martin \& Gourley-Delaney, 2014; Picker \& Berry, 2000); however, other elements such as teachers' images of mathematics and mathematicians, or the representations of mathematics and mathematicians in school materials, have been little studied (see for example Beswick, 2012). With this research we want to contribute to the study of the sources in school society - as defined by Rensaa (2006) - that can shape students' images of mathematics and mathematicians. In particular, our study has a double purpose: on the one hand, it focuses on identifying, classifying and describing the representations of mathematicians in Mexican lower secondary mathematics textbooks; on the other hand, our study problematizes the role of mathematics textbooks in the constitution of a dominant discourse around "the mathematician", and examines some of the consequences of such discourse in students' subjectivities.

Since the nineties, Levin and Mayer (1993) pointed out that the studies related to illustrations in textbooks, have focused mainly on the study of mathematical representations such as graphs and figures, but have left in the background the study of pictorial representations such as photos and illustrations. Although the interest in studying textbooks' illustrations, their functions and effects in the conceptualization has continued since then (see for example Liu and Qi, 2014), the representation of mathematicians in textbooks remains an unexplored area. Thus, a contribution of our study is to expand our knowledge about the potential effects that the representations of mathematicians that are included in textbooks may have on the students.

To develop our research, we analysed the bestselling Mexican mathematics textbooks for secondary level, which reach hundreds of thousands of children. Our analysis focused on identifying the representations of mathematicians in these textbooks. We believe that our research not only contributes to the study of sources in the school context that can shape the images students have of mathematicians, but also contributes to the study of representations of scientists and mathematicians in Latin American societies, which have been scarcely investigated (see for example De Gómezgil, 1975; Medina-Jerez, Middleton, \& Orihuela-Rabaza, 2011; Aguilar, Rosas, Zavaleta, \& Romo-Vázquez, 2016).

After this introduction we will continue with a review of the literature related to this study, namely studies on representations of mathematicians and studies on representations of scientists in textbooks; next we will describe the method we used to select the textbooks and guide their analysis; we then continue with a discussion of the representations of mathematicians identified in the textbooks, ending with a discussion of the results and their implications.

\section{A BRIEF REVIEW OF RESEARCH ON REPRESENTATIONS OF MATHEMATICIANS}

The research on representations of mathematicians in particular, and scientists in general, has its origin in the seminal work of Mead and Metraux (1957) about the image of the scientist among high school students. This was the first research study that revealed the existence of a stereotypical image of a scientist among students: a middleaged man, who may be unshaven and unkempt, working in a laboratory surrounded by instruments and conducting experiments. As the years passed, a research area specialised in the study of representations of scientists in different contexts and populations was developed; the results produced within this research area showed the persistence and ubiquity of these stereotypical perceptions over time and among different populations (see for example Chambers, 1983; Finson, 2002). Over time the studies on representations of scientists became more specialised, for example by discipline, resulting in the emergence of studies focused on representations of engineers, mathematicians and practitioners in other scientific careers.

One of the first collective efforts to investigate the popular image of mathematicians - and mathematics - can be traced back to the late eighties in the call for papers for the fifth ICMI study. There, Howson, Kahane and Pollak (1988) posed the following questions: "What is the popular view of a mathematician? To what extent does that view 
influence both the wish to study mathematics, or, should the possibility arise, to support mathematicians in their work?" (p. 208). From this moment, several research studies emerged addressing these questions from different perspectives.

\section{People's Images of Mathematicians}

The studies by Rock and Shaw (2000) and Picker and Berry (2000) were the first to reveal how students imagined mathematicians and the kind of work they carry out. Rock and Shaw (2000) ran a survey among 215 children from kindergarten through eighth grade (14-15 years old) where they were asked about the work of mathematicians (What do mathematicians do? What types of problems do mathematicians solve? What tools do mathematicians use?), and were also asked to draw mathematicians at work. They found that children tend to think that mathematicians do the same kind of mathematics that they do in the classroom, and that there is a lack of knowledge among the students about the types of work that mathematicians develop in the real world. With regard to their pictorial representations, they report that: "Most children's drawings showed smiling figures and more female than male figures; more than half indicated no definite racial characteristics" (pp. 553-554). On the other hand, Picker and Berry (2000) studied pictorial representations of mathematicians produced by 476 lower secondary school pupils (12-13 years old) from the USA, United Kingdom, Finland, Sweden, and Romania. They found that often mathematicians are depicted as teachers of mathematics - often using violence and intimidating students - but that they are also represented as a foolish person lacking common and fashion sense, or possessing special powers that may include magic potions and wizardry.

The presence of these stereotypical and negative images of mathematicians among people was subsequently confirmed in other studies with different populations. For example, Rensaa (2006) interviewed 31 adults about how they imagined mathematicians; she found that more than $40 \%$ of respondents have an image of a mathematician as being "a middle aged man with glasses, old-fashioned dressed and middle fitted, unsocial and boring" (p. 3). Similarly, Piatek-Jimenez (2008) explored the images that five female undergraduate mathematics students had about mathematicians; she found that the female students perceived mathematicians as exceptionally intelligent, obsessed with mathematics, and socially inept. It is important to note that there are studies suggesting that people who have a positive relationship with mathematics (e.g. they like mathematics or they are good mathematics students) have different images of mathematics and mathematicians, that is, less negative and more realistic images (Aguilar et al., 2014; Mendick, 2007).

\section{Representations of Mathematicians in Mass Media}

In one of the first studies of representations of mathematicians in mass media, Furinghetti (1993) explored the representations of mathematics and mathematicians in different films and literary works. She found that the mathematician is represented as a "meek man (until he rebels against vexation and injustice), absent-minded, naive and, generally speaking, biddable, but also endowed with clear (and sometimes strict) ideas about ethic and morals" (p. 36). Subsequent studies focused on identifying representations of mathematicians in popular culture found similar results; for example, by exploring how mathematicians are represented in movies, books, and songs, Wilson and Latterel (2001) find that mathematicians are often represented as troubled, mentally ill, or socially maladjusted individuals. In another example, Moreau et al. (2010) analyse the discourse in popular cultural texts, and conclude that mathematicians are generally represented as white, heterosexual, middle-class men.

Although several scholars suggest that the representations of mathematics and mathematicians that are present in mass media and popular culture can shape people's images, these representations are still poorly investigated. Particularly unexplored are the representations contained in school materials that are extensively distributed among pupils, such as textbooks, and which are the focus of this research. In the next section we review some studies on representations of scientists in textbooks, which are a precursor and inspiration for our study.

\section{REPRESENTATIONS OF SCIENTISTS IN TEXTBOOKS}

During recent years, research on mathematics textbooks has gained momentum because of the great interest that this research area has aroused within the international community of mathematics educators. The development of this research area manifests itself in a latent way through specialized conferences and publications. For instance, the International Conference on Mathematics Textbook Research and Development, the special issue of the journal ZDM focused on textbook research in mathematics education (Volume 45, Issue 5, September 2013), or the recently published ICME-13 Monograph (Fan, Trouche, Qi, Rezat, \& Visnovska, 2018). However, despite the apparent growth and importance of research on mathematics textbooks, the studies on representations of scientists in general and of mathematicians in particular, remain scarce. We do not know much about how these individuals are represented in mathematics textbooks. 
There are different arguments about the relevance of the study of representations of scientists and science itself in textbooks. For example, it is known that the representations contained in science textbooks influence the images of the nature of science that students and teachers possess (McComas, Almazroa, \& Clough, 1998); there is also evidence of the existence of similarities between students' images of science and scientists and the representations contained in the textbooks they use (She, 1995). It has been further argued that the representations of scientists in textbooks are a key factor in the lack of diversification in science, that is, a dearth of diversity - in terms of race, gender, cultural background, etc. - of the individuals that are depicted as scientists. Despite these arguments, not many studies have been conducted to understand how scientists are represented in textbooks around the world; even more rare are studies focused on studying representations of mathematicians in school materials.

Yacoubian, Al-Khatib and Mardirossian (2017) conducted a study of Lebanese textbooks and found stereotyped images of scientists that predominantly depict white men of European descent; the textbooks do not represent scientists from other regions of the world. In addition, scientists are presented as individuals working alone, who perform experiments in their laboratories following the scientific method and operating within Eurocentric paradigms.

In a pair of studies that analysed the representations of a select group of scientists in a sample of Canadian textbooks, van Eijck and Roth $(2008,2013)$ found that the representations of scientists in biology textbooks are inconsistent with the past and current practices of scientists; for example, the authors claim that the representations of scientists "largely ignores the process of scientific practice as mediated by a scientist's community and instead focuses on other scientists separated from the scientist in space and time" (2013, p. 24).

There are other studies focused on analysing diversity in the representations of science and scientists in textbooks; one of the reasons that it is important to have a great diversity in curriculum materials such as textbooks is that it encourages minority students to identify themselves with science and scientists. Brooks (2008) analysed five American physical science textbooks in which she identified a lack of diversity in the representations of scientists; for example, she found that the kind of scientists most often depicted in the textbooks were white men. According to the author, these representations perpetuate the stereotype that science is for white men. In a more recent study, Ceglie and Olivares (2012) analysed two American biology books focusing on the diversity of their representations; the researchers confirmed the results of Brooks (2008) in that the dominant representation of a scientist in these textbooks is that of a white man, while there is a glaring under-representation of black and Hispanic individuals.

The study reported in this paper will help to fill an evident gap in the research literature in mathematics education: the lack of studies on the representations of mathematicians contained in the textbooks used by mathematics students and teachers around the world. In the next section we explain the method we follow to develop the study.

\section{METHOD}

One of the purposes of this study is to identify and describe the representations of mathematicians contained in Mexican textbooks at lower secondary level; in this section we describe the method followed to achieve this aim. In particular we describe the process of selection of textbooks, as well as the concepts and questions that guided the analysis of the selected textbooks. Regarding the second purpose of the study, the problematization of the role of mathematics textbooks in the constitution of a dominant discourse on "the mathematician", such problematization is based on this analysis of the textbooks, and presented in the discussion section at the end of the paper.

\section{Selection of Textbooks}

Lower secondary education in Mexico is typically followed by students between 11 and 15 years old; it is divided into three grades, each with a duration of one year. For this study we selected the five bestselling textbooks for each grade level; thus, the total sample used in the study was fifteen textbooks. We decided to select textbooks of this educational level for our study because some authors point to this period as a sensitive one for the determination of students' attitudes towards mathematics (Aiken, 1970; Picker \& Berry, 2000).

To determine which textbooks are bestsellers at the lower secondary level in Mexico, we turned to the Catalogue of Free Textbooks, which is a report published by the Ministry of Education of Mexico (2015). This report indicates the circulation and distribution of each of the textbooks approved by the Ministry for its use in classrooms. The sample of selected textbooks is significant because, according to the official data, the selected titles reach a total of $4,000,321$ children, and represent more than the $54 \%$ of the total number of textbooks distributed at the lower secondary level in Mexico. Table 1 indicates the fifteen textbooks selected for this study, their positions in the sales 
Table 1. Bestselling mathematics textbooks at lower secondary level in Mexico

\begin{tabular}{|c|c|c|c|}
\hline & $\begin{array}{l}\text { Distribution } \\
\text { ranking position }\end{array}$ & Textbook & $\begin{array}{c}\text { Number of } \\
\text { items } \\
\text { distributed }\end{array}$ \\
\hline \multirow{5}{*}{$\begin{array}{c}\text { First } \\
\text { grade }\end{array}$} & 1 & Block, S.D. \& García, P.S. (2015) & 271,649 \\
\hline & 2 & Arriaga, R.A. \& Benítez, C.M.M. (2015a) & 202,852 \\
\hline & 3 & Hernández, Z.P., Hernández, H.M. \& Magallanes, G.G. (2014) & 111,216 \\
\hline & 4 & Sánchez, S.F. (2015a) & 101,316 \\
\hline & 5 & Escareño, F. \& López, E.O.L. (2015a) & 67,639 \\
\hline \multirow{5}{*}{$\begin{array}{l}\text { Second } \\
\text { grade }\end{array}$} & 1 & García, P.S. \& Block, S.D. (2015) & 282,342 \\
\hline & 2 & Arriaga, R.A. \& Benítez, C.M.M. (2015b) & 175,325 \\
\hline & 3 & Sánchez, S.F. (2015b) & 109,524 \\
\hline & 4 & Ramírez, C.M., Castillo, C.R., Vergara, R.D., Flores, O.M.E. \& Azpeitia, V.J.G. (2015a) & 95,129 \\
\hline & 5 & Xique, A.J.C. (2015) & 74,274 \\
\hline \multirow{5}{*}{$\begin{array}{l}\text { Third } \\
\text { grade }\end{array}$} & 1 & Block, S.D., Mendoza, V.D.B., García, P.S. \& García, Z.J.C. (2015) & 256,356 \\
\hline & 2 & Arriaga, R.A. \& Benítez, C.M.M. (2015c) & 178,965 \\
\hline & 3 & Escareño, F. \& López, E.O.L. (2015b) & 102,194 \\
\hline & 4 & De Icaza, P.A. (2015) & 68,677 \\
\hline & 5 & Ramírez, C.M., Castillo, C.R., Vergara, R.D., Flores, O.M.E. \& Azpeitia, V.J.G. (2015b) & 74,998 \\
\hline
\end{tabular}

ranking for each grade, and the number of items distributed. In the appendix the complete references of the selected textbooks are included.

\section{What Counted as a Representation in this Study?}

According to Goldin (2014), the term "representation" refers to: visible or tangible productions such as a graph or a formula (an external representation), mental or cognitive constructs of people (an internal representation), or even act or process of inventing or producing representations. During the analysis of the textbooks it was noticed that the format of the representations of mathematicians varied. For instance, there were images depicting wellknown mathematicians or representing groups of people performing some mathematical activity; there were also texts describing, for example, the work or contribution of a particular mathematician. Thus, with the aim of using a unit of analysis covering the range of representations that could be found in the selected textbooks, we decided to consider as a representation not only text but also drawings, photographs, and illustrations in general.

\section{What was Considered as a Mathematician?}

In the study the term mathematician was understood in a broad sense; that is, a mathematician was considered to be any person (or group of people) that in the textbook either (1) was explicitly referred to as a mathematician, (2) was credited with the development of a mathematical concept or tool, or (3) was displayed performing some sort of mathematical activity (such as counting, modelling, etc.).

After the concepts of representation and mathematician were defined, we proceeded to analyse each book, page by page, to identify all the representations of mathematicians; if there was discrepancy or doubt about the way a representation should be interpreted, an explicit discussion was organised to try to reach a consensus on its interpretation. Once a representation of a mathematician was located, we focused our attention on six aspects of the representation. Such aspects served as a basis for the coding of the representations of mathematicians. They were constructed taking into consideration some of the research results reported in the literature on representations of scientists in textbooks. The six aspects and their rationale are presented next:

1. Individuals or groups of persons represented. There are studies showing that scientists are often represented working alone, thus denying the social and collective nature of the production of knowledge (Al-Khatib \& Mardirossian, 2017; van Eijck \& Roth, 2013). Thus, we were interested in knowing if mathematicians were represented individually or collectively, in order to identify the kind of perspective on mathematical activity that was favoured in the textbooks. In addition, it was decided if the individual or group represented was identifiable, that is, if it was the representation of a "known mathematician" (such as Pythagoras or the Maya). This identification was a basic element in the analysis, since it allowed to count the frequency of the mathematicians represented, as well as the application of the subsequent codes.

2. Period of time when the represented mathematician lived. Another aspect of interest was determining whether the textbooks promoted an image of the mathematician as someone who lived in ancient times, or as a contemporary individual. This is an aspect that we think may contribute to the constitution of a poor conception among students about mathematicians, namely, to perceive them as people who lived in antiquity, without a 
Table 2. Gender, geographical origin, and time period of the most frequently represented mathematicians in the mathematics textbooks of first grade

\begin{tabular}{|c|c|c|c|c|c|}
\hline & & Frequency & Period of time in which they lived & Geographical origin & Gender \\
\hline \multirow{7}{*}{$\begin{array}{l}\text { Mathematicians } \\
\text { most frequently } \\
\text { represented }\end{array}$} & Thales of Miletus & 9 & c. 620 B.C.E. -546 B.C.E. & Western Europe & Male \\
\hline & Pythagoras & 6 & C. 570 B.C.E. -495 B.C.E. & Western Europe & Male \\
\hline & Eratosthenes & 4 & c. 276 B.C.E. -195 B.C.E. & Western Europe & Male \\
\hline & Euclid & 3 & c. 330 B.C.E. -260 B.C.E & Western Europe & Male \\
\hline & Isaac Newton & 3 & $1643-1727$ & Western Europe & Male \\
\hline & Babylonians & 3 & C. 1792 B.C.Е.-539 B.C.Е & Near East & Group \\
\hline & Ancient Egyptians & 3 & C. 3150 B.C.E.-31 B.C.E & Mediterranean Africa & Group \\
\hline
\end{tabular}

connection nor presence in modern societies. Thus, we tried to determine-by consulting external sources of information such as encyclopedias - the time when the mathematicians depicted were alive in order to determine whether the representations included in the textbooks were of ancient or contemporary mathematicians.

3. Geographic origin of the represented mathematician. Considering the studies of Brooks (2008); Ceglie and Olivares (2012) that highlight the importance of diversity in the representations of scientists in textbooks, we identify the geographical origin of mathematicians represented in textbooks, taking as reference "The cultural regions of the world" (Ministry of Education of Mexico 2010, p. 17) North America, Latin America, Western Europe, Eastern Europe, Mediterranean Africa, Africa, Near East, Middle East, Far East, Indochina and Oceania.

4. Gender of the mathematician represented. Since there is research pointing out the under-representation of women in science textbooks (Pienta \& Smith, 2012), there was an interest in identifying the proportion of female mathematicians represented in the textbooks considered in the study. Thus, when possible, the representations of mathematicians were classified as female (woman), male (man), or group (when there was a representation of a group of people). There was not much room for differing interpretations of the masculine and feminine categories since, as we shall see in the results section, the representations of female mathematicians were almost nil.

5. Role of the representation. It is known that the textbooks illustrations that are related to their accompanying text, are more effective in promoting understanding than those illustrations that only have a "decorative" role (Levin \& Mayer, 1993, pp. 106-107). For this reason, in addition to identifying the representations of mathematicians, it was sought to determine the role that these representations play in the lesson where they appeared. To organize the results, the following two categories were used: (1) the representation is used to illustrate a concept or to introduce a mathematical activity, or (2) the representation is not used to introduce an activity nor a concept, but only has ornamental or anecdotal value.

6. Format of the representation. Finally, the representations were classified according to their format. It is important to identify the format in which the illustrations appear, since different research studies indicate that when pictures are incorporated into text material, the memory for that material can be improved (see Mandl \& Levin, 1989; Willows \& Houghton, 1987). Thus, the representations of mathematicians in this study were classified as (1) textual descriptions, or (2) illustrations - such as photographs or drawings.

The coding of the representations of mathematicians was performed independently, we constituted three teams of two members each, to perform the coding separately. Subsequently, the teams met to try to achieve a consensus on the coding. As in the previous phase where the representations of mathematicians were identified, discrepancies over the coding were solved through collective dialogue, however, these discrepancies were not significant nor frequent. Once consensus was reached, the information associated with each of the six aspects of the representations of mathematicians, was concentrated in spreadsheets to facilitate its further interpretation.

Next we present the results obtained after identifying and coding the representations of mathematicians contained in the mathematics textbooks included in this study.

\section{RESULTS}

In total, 158 representations of mathematicians were found in the fifteen textbooks analysed: 75 in the first grade textbooks, 32 in the second grade textbooks, and 51 in the textbooks for third grade. Below we present the results concerning the mathematicians most frequently represented in the textbooks, organized by school grade.

\section{Representations of Mathematicians in the First Grade Textbooks}

Among the most frequently represented mathematicians in the first grade mathematics textbooks are: Thales of Miletus (represented nine times), Pythagoras (represented six times), and Eratosthenes (represented four times). Table 2 shows more information about the most frequently represented mathematicians. 


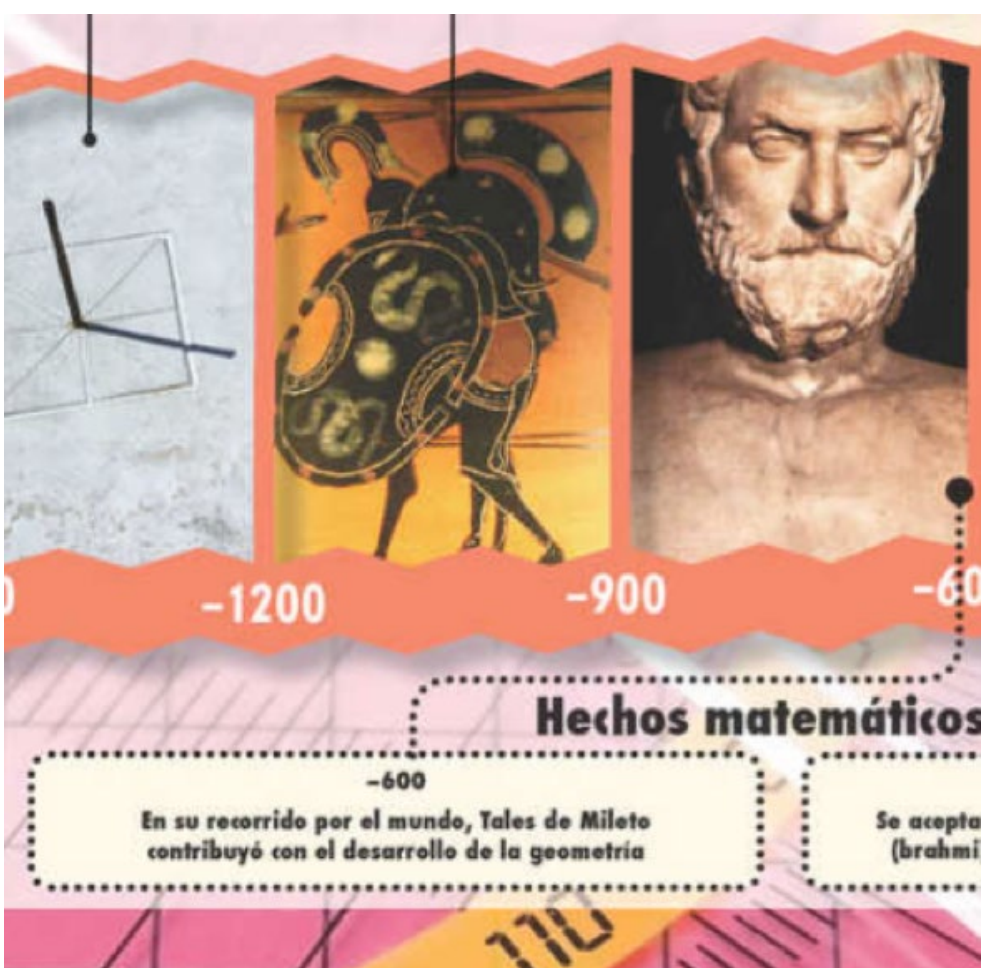

Figure 1. Representation of Thales of Miletus with an anecdotic value, included in the textbook by Arriaga and Benítez (2015a)

As for the roles played by the representations of mathematicians in the first grade textbooks, most (56) are representations that do not serve to introduce a mathematical activity or a specific topic, but only have anecdotal value; nineteen representations are used to introduce some mathematical activity or to illustrate a concept. An example of a representation with an anecdotic value is the representation of Thales of Miletus in the textbook by Arriaga and Benítez (2015a). This representation consists of a photograph of a sculpture of Thales of Miletus, which is used as part of a timeline that appears as a front page for one of the units of the textbook (see Figure 1); the picture of the sculpture representing Thales of Miletus is located in the timeline about the year 600 B.C.E. and is accompanied by the following caption: "In his traveling around the world, Thales of Miletus contributed to the development of geometry" (our translation, p. 67).

An example of a representation that is used to introduce a mathematical activity is the following extract from Sánchez (2015a) in which Eratosthenes is mentioned as the person who found a method to locate prime numbers, the Sieve of Eratosthenes, and the reader is asked to determine certain prime numbers using this algorithm:

"Hector and Yolanda discovered that Eratosthenes found a method to locate the prime numbers that appear in a sequence, this procedure is called the Sieve of Eratosthenes.

Determine the prime numbers between 1 and 150, following the method of Eratosthenes [Next the algorithm is illustrated step by step]" (p. 74, our translation).

Regarding the format of the identified representations, the majority (72) are textual descriptions, while three are illustrations. An example of an illustration of a mathematician is the picture of Thales of Miletus described above; an example of a textual description of a mathematician is the following text referring to Pythagoras taken from Escareño and Lopez (2015a):

"Pythagoras was a Greek mathematician who taught around 580 B.C.E. He considered sacred the number 10, written in a triangular shape, and he called it Trianon" (p. 25, our translation).

\section{Representations of Mathematicians in the Second Grade Textbooks}

In second grade textbooks the ancient Egyptians were the most frequently represented mathematicians (four times). Other mathematicians frequently represented are reported in Table 3. 
Table 3. Gender, geographical origin, and time period of time of the most frequently represented mathematicians in the mathematics textbooks of second grade

\begin{tabular}{|c|c|c|c|c|c|}
\hline & & Frequency & $\begin{array}{l}\text { Period of time in which they } \\
\text { lived }\end{array}$ & Geographical origin & Gender \\
\hline \multirow{6}{*}{$\begin{array}{l}\text { Mathematicians } \\
\text { most frequently } \\
\text { represented }\end{array}$} & Ancient Egyptians & 4 & c. 3150 B.C.E.-31 B.C.E & Mediterranean Africa & Group \\
\hline & Archimedes & 2 & c. 287 B.C.E. -212 B.C.E & Western Europe & Male \\
\hline & Diophantus & 2 & c. 201 C.E.-285 C.E & Western Europe & Male \\
\hline & Al-Khawarizmi & 2 & c. 780 C.E. -850 C.E & Near East & Male \\
\hline & Robert Boyle & 2 & $1627-1691$ & Western Europe & Male \\
\hline & Blaise Pascal & 2 & $1623-1662$ & Western Europe & Group \\
\hline
\end{tabular}

Table 4. Gender, geographical origin, and time period of time of the most frequently represented mathematicians in the mathematics textbooks of third grade

\begin{tabular}{|c|c|c|c|c|c|}
\hline & & Frequency & $\begin{array}{l}\text { Period of time in which they } \\
\text { lived }\end{array}$ & Geographical origin & Gender \\
\hline \multirow{6}{*}{$\begin{array}{l}\text { Mathematicians } \\
\text { most frequently } \\
\text { represented }\end{array}$} & Ancient Egyptians & 4 & c. 3150 B.C.E. -31 B.C.E & Mediterranean Africa & Group \\
\hline & Archimedes & 4 & c. 287 B.C.E. -212 B.C.E & Western Europe & Male \\
\hline & Fibonacci & 3 & $1170-1250$ & Western Europe & Male \\
\hline & Eratosthenes & 2 & c. 276 B.C.E.-C. 195 B.C.E. & Western Europe & Male \\
\hline & Leonardo da Vinci & 2 & $1452-1519$ & Western Europe & Male \\
\hline & Ancient Indians & 2 & C. 7000 B.C.E. -500 C.E & Middle East & Group \\
\hline
\end{tabular}

Regarding the role of the representations of mathematicians in the second grade textbooks, eighteen are representations with an anecdotic value, while fourteen serve to introduce some mathematical activity or to illustrate a concept.

Concerning the format of the representations, 28 are textual descriptions of mathematicians, and four are illustrations.

\section{Representations of Mathematicians in the Third Grade Textbooks}

As in the textbooks for second grade, the ancient Egyptians and Archimedes are among the most frequently represented mathematicians in the third grade textbooks. Other mathematicians frequently represented are shown in Table 4.

The representations of mathematicians in the selected third grade textbooks appear most often as isolated elements without an explicit connection to the topic addressed; out of a total of 51 representations, 35 appear as anecdotal elements, while sixteen serve to introduce mathematical activities or to illustrate concepts.

Regarding the format of the representations, 44 are textual descriptions of mathematicians while seven are illustrations of mathematicians.

\section{DISCUSSION}

The results of this research show that the analysed textbooks contain representations of mathematicians that can favour the construction of stereotypical images of mathematicians among students, such as those that have been previously reported in the literature (Picker \& Berry, 2000; Rock \& Shaw, 2000).

Observe for instance the individuals or groups of persons most often represented (with a frequency equal to or greater than four) and the period of time when they lived: Thales of Miletus, Pythagoras, Eratosthenes, the ancient Egyptians, and Archimedes. This is only a sample of a more general phenomenon, namely, that these textbooks expose students mainly to representations of mathematicians who lived several centuries ago. We believe that the predominance of representations of ancient mathematicians does not favour the construction of an image of a mathematician who has a role in modern societies; in our analysis we found few representations of contemporary mathematicians and their work; in particular, in all the textbooks analysed only eleven representations of mathematicians who lived in the 20th century were found-for example Andrew Wiles, George Stibitz, and Wolfgang Haken. It could be argued that the prevalence of representations of ancient mathematicians in these textbooks is due to the fact that most of the mathematical topics addressed at this level were developed precisely by ancient mathematicians - as in the case of the Pythagorean theorem; however, as we have shown in the results of this study, most of the time the representations of these ancient mathematicians do not serve to introduce a mathematical concept or activity. Rather, the representations have an anecdotic or ornamental role. As will be discussed later in this section, this kind representation with an anecdotic role represents an area of opportunity to 
broaden the diversity of representations of mathematicians and promote a richer image of them, not limited to representations of ancient mathematicians.

With regard to the geographical origin of the mathematicians represented in the textbook sample, it is remarkable that the representations are predominantly from Western Europe. Despite the fact that these are textbooks aimed at Mexican students, none includes representations of Mexican mathematicians nor representations of regional ethnic groups that have been prominent in the application and development of mathematics, such as the Mayan for instance; an exception is the textbook by Ramírez, Castillo, Vergara, Flores and Azpeitia, (2015b) which mentions Mesoamerican people and the Nariño culture from Colombia. We believe that the prevalence of representations of white European mathematicians encourages the grounding of a stereotype present in several students, namely that scientists and mathematicians possess such particular racial origin (Chambers, 1983; Mendick, Moreau, \& Hollingworth, 2008; Picker \& Berry, 2000); on the other hand, as has been argued in studies on diversity in representations of scientists in textbooks, the lack of racial diversity in representations of scientists in textbooks can hinder students from minority racial groups in identifying themselves as possible or potential scientists; in the same way we believe that the absence of representations of mathematicians of American Indian origin does not encourage Mexican students, at whom these textbooks are aimed, to identify themselves as people who could become mathematicians in the future.

In their study on the gendering of representations of mathematics and mathematicians in popular culture, Mendick et al. (2008) declare that the popular culture texts strongly support the association of mathematics with masculinity through three mechanisms: "the dominant representations of mathematicians being men, the disappearing of women's mathematical contributions and the ways that women doing mathematics are subordinated in a range of ways including their youth and their positioning as appendages to 'greater' male mathematicians" (p. ii). Our study shows that the analysed textbooks have a gendered representation, an eminently male representation of mathematicians, that is achieved through the first of the mechanisms mentioned by Mendick et al. (2008), the dominant representations of mathematicians being men: out of a total of 158 representations of mathematicians identified in the textbooks, we located only one representation of a woman, Hypatia the Greek mathematician. This dominant representation of mathematicians as men in mathematics textbooks could encourage women to produce masculinized images of mathematicians, which in turn could hinder their identification of themselves as potential members of the community of mathematicians and discourage them from pursuing further studies in mathematics (Piatek-Jimenez, 2008).

Concerning the role of the representations of mathematicians in the lessons of the textbooks, the results show that out of the 158 representations identified, 109 are representations that do not serve to introduce any concept or mathematical activity. They are mostly representations of ancient mathematicians who have an anecdotal role in the lesson; these representations are used in a small grain size illumination approach, as discussed by Jankvist (2009). The role of the remaining 49 representations is to introduce some activity or mathematical concept. Our point here is that if the majority of the representations are not necessarily related to the topic or to the mathematical activities in the lesson, then this is an area of opportunity that could be used to enhance and diversify the representations of mathematicians included in the textbooks, in order to foster a richer, more diverse and updated image of a mathematician among students. This universe of representations of mathematicians with an anecdotal or ornamental role could be enriched by including representations of contemporary mathematicians, female mathematicians, mathematicians coming from racial, cultural, and social minority groups, children and youth participating in mathematical competences, etc. The opportunities to enrich the representations of mathematicians in textbooks are vast.

A finding about the format of the representations of mathematicians in the textbooks analysed is that most (144) are textual descriptions of mathematicians, while the rest (14) are graphic illustrations of mathematicians. Both types of representations have different qualities; for instance, the graphic illustrations of mathematicians allow students to associate with the mathematician represented a face, a style of hair or clothing, etc. It is not clear to us and it is beyond of the scope of this study to investigate - if the nature of the textual descriptions of mathematicians affect the constitution of students' images of mathematicians in the same way or with the same intensity as the illustrations do. For instance, Picker and Berry (2000) analysed the images that students from five countries had of mathematicians, through drawings that they produced; the researchers found that in all countries there was at least one drawing of Albert Einstein, which, according to the researchers, indicates that these images come from sources such as the media, comic books, and cartoons. As can be noticed, those are sources filled with illustrations and graphical components. However, since the descriptive and textual nature is one of the characteristics of most of the representations identified in the textbooks, we believe it is an aspect that could be further investigated in the future.

\section{A Dominant Discourse Supported by Mathematics Textbooks}

In this section we address the second purpose of this study, which is to problematize the role of mathematics textbooks in the formation of a dominant discourse on "the mathematician". As can be noticed, the analysis of 
Mexican textbooks produces results very similar to those reported in the research on representations of mathematicians. This is, our results show stereotyped representations of mathematicians, such as those that have been identified around the world in other mass media, and in different populations. Although these stereotyped images have been identified in different communities and contexts, we think that these are discursive regularities that constitute a dominant discourse about who and how mathematicians are.

The problem, as we see it, is that this discourse shapes and influences the way in which mathematicians are perceived, but also, it is a discourse that constitutes taken-for-granted truths about mathematicians and their activity, and positions the students with respect to mathematics. That is, it is a discourse that impacts the subjectivity of the student and indicates whether he or she is a suitable or adequate person to develop mathematics. For example, our results show that the textbooks analysed promote a discourse from which women are practically exiled, we can affirm that such discourse generates a certain "reality" that presents mathematics as a masculine enterprise. As noted by Dowling (1998), the point here is not only whether the textbook provides "appropriate role models" for girls, the problem rather is that this discourse contributes to create a perception about what it means to be a woman in the world of mathematics, and apparently is a world where women are definitely not its protagonists.

The Mexican students who are exposed to this discourse on the representations of mathematicians, experience a situation similar to that encountered by the female students. The discourse that these textbooks promote erases all trace of the uses and mathematical developments that took place in the region that today is known as Mexico and Latin America. We argue that such discourse legitimizes some social groups as capable of developing mathematics and represents them as outstanding in this human activity, but in which neither Mexicans nor their ancestors have participatory roles. Such discourse favours dividing practices in which certain social groups are classified as able to contribute to the development of mathematics, while others are not.

We call on mathematics textbook researchers, authors, and mathematics teachers, to conceptualize the textbook as a device that disseminates this type of discourse in the school society, particularly in the mathematics classroom. If we want all our students to feel included in the world of mathematics - regardless of their gender or sociocultural background -, and perceive themselves as competent people to develop them, then we need to begin to question ourselves, the representations about the mathematicians that are included in the mathematics textbooks. The mathematics classroom could function as a suitable experimentation space to identify, question and discuss with the students, the stereotyped images about mathematicians that may be present in their textbooks. Other future research directions that could be pursued in future studies are mentioned in the next section of the article.

\section{Some Directions for Future Research}

The results of this research show that the bestselling mathematics textbooks for the lower secondary level in Mexico privilege representations of mathematicians that could perpetuate students' stereotypes, such as the idea that a mathematician is a white man. Are the representations of mathematicians included in lower secondary textbooks from other regions of the world similar to or different from those reported in this study? Do representations of ancient mathematicians prevail in other textbooks? Is there a lack of representations of female mathematicians? These and other questions could be answered by research studies similar to the one reported in this article, conducted in other regions of the world; comparative studies such as those made in other areas of textbook research (see for example Kim, 2012) would also help to expand our knowledge of representations of mathematicians in mathematics textbooks.

Primary school is another context in which it would be relevant to develop this type of research. Due to the large number of children who are educated using mathematics textbooks in this educational level, and because it is an important stage in the development of attitudes towards mathematics, it would be important to extend this kind of research to include the analysis of the representations of mathematicians included in the mathematics textbooks at primary level.

Finally, we believe it is important to devise mechanisms to make those people responsible for designing and writing mathematics textbooks familiar with the results reported in this article. It is relevant that publishers, designers, and authors of mathematics textbooks be aware of the key role that the representations of mathematicians contained in the textbooks, may have in the constitution of students' images and attitudes towards mathematics. Furthermore, it is important that they know that several of the books that they produce and the students consume may be filled with stereotypical representations that do not contribute to the formation of a rich, diverse, and updated image of the mathematician. 


\section{REFERENCES}

Aguilar, M. S., Rosas, A., Zavaleta, J. G. M., \& Romo-Vázquez, A. (2016). Exploring high-achieving students' images of mathematicians. International Journal of Science and Mathematics Education, 14(3), 527-548. https:/ / doi.org/10.1007/s10763-014-9586-1

Aiken, L. R (1970). Attitudes toward mathematics. Review of Educational Research, 40(4), 551-596. https://doi.org/10.3102/00346543040004551

Beswick, K. (2012). Teachers' beliefs about school mathematics and mathematicians' mathematics and their relationship to practice. Educational Studies in Mathematics, 79(1), 127-147. https:/ / doi.org/10.1007/s10649011-9333-2

Brooks, K. M. (2008). A content analysis of physical science textbooks with regard to the nature of science and ethnic diversity. Retrieved from ProQuest Dissertations and Theses (UMI Number: 3309542).

Ceglie, R., \& Olivares, V. (2012). Representation of diversity in science textbooks. In H. Hickman \& B.J. Porfilio (Eds.), The New Politics of the Textbook. Problematizing the Portrayal of Marginalized Groups in Textbooks (pp. 4968). Rotterdam: Sense Publishers. https:/ / doi.org/10.1007/978-94-6091-912-1_4

Chambers, D. W. (1983). Stereotypic images of the scientist: The draw-a-scientist test. Science Education, 67(2), 255265. https:/ / doi.org/10.1002/sce.3730670213

De Gómezgil, M. L. R. S. (1975). Mexican adolescents' image of the scientist. Social Studies of Science, 5(3), 355-361. https:/ / doi.org/10.1177/030631277500500306

Dowling, P. (1998). The Sociology of Mathematics Education: Mathematical Myths/Pedagogic Texts. London: The Falmer Press.

Evans, J., Tsatsaroni, A. \& Czarnecka, B. (2014). Mathematical images in advertising: Constructing difference and shaping identity, in global consumer culture. Educational Studies in Mathematics, 85(1), 3-27. doi: 10.1007/s10649-013-9496-0

Fan, L., Trouche, L., Qi, C., Rezat, S., \& Visnovska, J. (Eds.). (2018). Research on Mathematics Textbooks and Teachers' Resources. Advances and Issues. Cham: Springer. https:/ / doi.org/10.1007/978-3-319-73253-4

Finson, K. D. (2002). Drawing a scientist: What we do and do not know after fifty years of drawings. School Science and Mathematics, 102(7), 335-345. https:// doi.org/10.1111/j.1949-8594.2002.tb18217.x

Furinghetti, F. (1993). Images of mathematics outside the community of mathematicians: Evidence and explanations. For the Learning of Mathematics, 13(2), 33-38.

Goldin, G. A. (2014). Mathematical representations. In Lerman, S. (Ed.), Encyclopedia of Mathematics Education (pp. 409-413). The Netherlands: Springer. https:/ / doi.org/10.1007/978-94-007-4978-8_103

Howson, A. G., Kahane, J.-P. \& Pollak, H. (1988). The popularization of mathematics. L'Enseignement Mathématique, 34, 205-212. https://doi.org/10.5169/seals-56594

Jankvist, U. T. (2009). A categorization of the "whys" and "hows" of using history in mathematics education. Educational Studies in Mathematics, 71(3), 235-261. https:/ / doi.org/10.1007/s10649-008-9174-9

Kim, R. Y. (2012). The quality of non-textual elements in mathematics textbooks: An exploratory comparison between South Korea and the United States. ZDM - The International Journal on Mathematics Education, 44(2), 175-187. https:/ / doi.org/10.1007/s11858-012-0399-9

Levin, J. R., \& Mayer, R. E. (1993). Understanding illustrations in text. In B. K. Britton, A. Woodward, \& M. R. Binkley (Eds.), Learning from textbooks: Theory and Practice (pp. 95-111). Hillsdale, NJ: Lawrence Erlbaum Associates.

Liu, X., \& Qi, C. (2014). A comparative study of illustrations in the old and new middle school mathematics textbooks in China. In K. Jones, C. Bokhove, G. Howson \& L. Fan (Eds), Proceedings of the International Conference on Mathematics Textbook Research and Development (ICMT-2014) (pp. 563-568). UK: The University of Southampton.

Mandl, H., \& Levin. J. R. (Eds.). (1989). Knowledge Acquisition from Text and Pictures. North-Holland: Elsevier.

Martin, L., \& Gourley-Delaney, P. (2014). Students' images of mathematics. Instructional Science, 42(4), 595-614. https://doi.org/10.1007/s11251-013-9293-2

McComas, W. F., Almazroa, H., \& Clough, M. P. (1998). The nature of science in science education: An introduction. Science E Education, 7(6), 511-532. https:/ / doi.org/10.1023/A:1008642510402

Mead, M., \& Métraux, R. (1957). Image of the scientist among high-school students. Science, 126(3270), $384-390$. https://doi.org/10.1126/science.126.3270.384 
Medina-Jerez, W., Middleton, K.V. \& Orihuela-Rabaza, W. (2011). Using the DAST-C to explore Colombian and Bolivian students' images of scientists. International Journal of Science and Mathematics Education, 9(3), 657690. https:/ / doi.org/10.1007/s10763-010-9218-3

Mendick, H. (2005). Mathematical stories: Why do more boys than girls choose to study mathematics at AS-level in England? British Journal of Sociology of Education, 26(2), 225-241. https:/ / doi.org/10.1080/0142569042000294192

Mendick, H. (2007). Mathematical images and identities: Education, entertainment, social justice. Full research report ESRC end of award report [RES-000-23-1454]. Swindon: ESRC. Retrieved from http:/ / www.leeds.ac.uk/educol/documents/190670.pdf

Mendick, H., Moreau, M.-P., \& Hollingworth, S. (2008). Mathematical images and gender identities. A report on the gendering of representations of mathematics and mathematicians in popular culture and their in influences on learners. UK Resource Centre for Women in Science, Engineering and Technology: Bradford, UK.

Ministry of Education of Mexico (2014). Libros de texto gratuitos, ciclo escolar 2015-2016, Catálogo [Free textbooks, school year 2015-2016, Catalogue]. Mexico: Secretaría de Educación Pública. Retrieved from http:/ / www. conaliteg.gob.mx/images/stories/libros/2015-07-21_catalogo_libros_texto_gratuitos_2015.pdf

Ministry of Education of Mexico (2010). Geografía Sexto Grado. Mexico: Secretaría de Educación Pública.

Moreau, M.-P., Mendick, H., \& Epstein, D. (2010). Constructions of mathematicians in popular culture and learners' narratives: A study of mathematical and non-mathematical subjectivities. Cambridge Journal of Education, 40(1), 25-38. https:/ / doi.org/10.1080/03057640903567013

Piatek-Jimenez, K. (2008). Images of mathematicians: A new perspective on the shortage of women in mathematical careers. ZDM - The International Journal on Mathematics Education, 40(4), 633-646. https:/ / doi.org/10.1007/s11858-008-0126-8

Picker, S. H., \& Berry, J. S. (2000). Investigating pupils' images of mathematicians. Educational Studies in Mathematics, 43(1), 65-94. https://doi.org/10.1023/A:1017523230758

Pienta, R. S., \& Smith, A. M. (2012). Women on the margins. The politics of gender in the language and content of science textbooks. In H. Hickman \& B.J. Porfilio (Eds.), The New Politics of the Textbook. Problematizing the Portrayal of Marginalized Groups in Textbooks (pp. 33-47). Rotterdam: Sense Publishers. https:/ / doi.org/10.1007/978-94-6091-912-1_3

Rensaa, R. J. (2006). The image of a mathematician. Philosophy of Mathematics Education Journal, 19, 1-18.

Rock, D., \& Shaw, J. M. (2000). Exploring children's thinking about mathematicians and their work. Teaching Children Mathematics, 6(9), 550-555.

She, H.-C. (1995). Elementary and middle school students' image of science and scientists related to current science textbooks in Taiwan. Journal of Science Education and Technology, 4(4), 283-294. https:/ / doi.org/10.1007/BF02211260

van Eijck, M., \& Roth, W.-M. (2008). Representations of scientists in Canadian high school and college textbooks. Journal of Research in Science Teaching, 45(9), 1059-1082. https:/ / doi.org/10.1002/tea.20259

van Eijck, M. \& Roth, W.-M. (2013). The heroes of science. In M. van Eijck \& W.-M. Roth (Eds.), Imagination of Science in Education. From Epics to Novelization (pp. 3-25). Dordrecht: Springer. https:/ / doi.org/10.1007/978-94-0075392-1_1

Willows. D. M., \& Houghton. H. A. (Eds.). (1987). The Psychology of Illustration. Volume 1 Basic Research. New York: Springer.

Wilson, J. L., \& Latterell, C. M. (2001). Nerds? or nuts? Pop culture portrayals of mathematicians. ETC: A Review of General Semantics, 58(2), 172-178.

Yacoubian, H. A., Al- Khatib, L., \& Mardirossian, T. (2017). Analysis of the image of scientists portrayed in the Lebanese national science textbooks. Science E Education 26(5), 513-528. https://doi.org/10.1007/s11191017-9908-0 


\section{APPENDIX}

\section{Mathematics Textbooks Selected for the Study}

Arriaga, R. A., \& Benítez, C. M. M. (2015a). Matemáticas por competencias 1. Mexico: Pearson Educación. Arriaga, R. A., \& Benítez, C. M. M. (2015b). Matemáticas por competencias 2. Mexico: Pearson Educación. Arriaga, R. A., \& Benítez, C. M. M. (2015c). Matemáticas por competencias 2. Mexico: Pearson Educación. Block, S. D., \& García, P. S. (2015). Matemáticas 1. Conect@ Estrategias. Mexico: Ediciones SM.

Block, S. D., Mendoza, V. D. B., García, P. S., \& García, Z. J. C. (2015). Matemáticas 3. Conect@ Estrategias. Mexico: Ediciones SM.

De Icaza, P. A. (2015). Matemáticas 3. Serie Todos Juntos. Mexico: Santillana.

Escareño, F., \& López, E. O. L. (2015a). Matemáticas 1. México: Trillas.

Escareño, F., \& López, E. O. L. (2015b). Matemáticas 3. México: Trillas.

García, P. S., \& Block, S. D. (2015). Matemáticas 2. Conect@ Estrategias. Mexico: Ediciones SM.

Hernández, Z. P., Hernández, H. M., \& Magallanes, G. G. (2014). Matemáticas 1. Mexico: Ek Editores.

Ramírez, C. M., Castillo, C. R., Vergara, R. D., Flores, O. M. E., \& Azpeitia, V. J. G. (2015a). Matemáticas 2. Desafíos Matemáticos. Mexico: Fernández Educación.

Ramírez, C. M., Castillo, C. R., Vergara, R. D., Flores, O. M. E., \& Azpeitia, V. J. G. (2015b). Matemáticas 3. Desafíos Matemáticos. Mexico: Fernández Educación.

Sánchez, S. F. (2015a). Matemáticas 1. Construcción del pensamiento. Serie Evolución. Mexico: Fernández Educación.

Sánchez, S. F. (2015b). Matemáticas 2. Construcción del pensamiento. Serie Evolución. Mexico: Fernández Educación.

Xique, A. J. C. (2015). Jaque Mate 2. México: Ediciones Larousse.

\section{http://www.ejmste.com}

